2. Castiglione F, Diaferia M, Morace F, Labianca O, Meucci $\mathrm{C}$ et al. Risk factors for inflammatory bowel diseases according to the "hygiene hypothesis": a case-control, multi-centre, prospective study in Southern Italy. J Crohns Colitis. 2012;6:324-9. doi: 10.1016/j.crohns.2011.09.003.

3. Belli A, Coppola MG, Petrullo L, Lettieri G, Palumbo C, Dell'Isola C, Smeraglia R, Triassi M, Spada E, Amoroso P. The current spectrum and prevalence of intestinal parasitosis in Campania (region of southern Italy) and their relationship with migration from endemic countries. International Journal of Infectious Diseases 2014;29:4247. doi: 10.1016/j.ijid.2014.04.021

4. Calderaro A, Montecchini S, Rossi S, Gorrini C, De Conto F, Medici MC, Chezzi C, Arcangeletti MC. Intestinal parasitoses in a tertiary-care hospital located in a non-endemic setting during 2006-2010. BMC Infectious Diseases 2014, 14:264. doi:10.1186/1471-2334-14-264

5. Singh UC, Kumar A, Srivastava A, Patel B, Shukla VK, Gupta SK. Small bowel stricture and perforation: an unusual presentation of Fasciolopsisbuski. Trop Gastroenterol. 2011;32:320-2.

\section{Endoscopic Closure of Tuberculous Esophago- Bronchial Fistula Using The Over-The-Scope-Clip System}

Tuberculosis is the commonest cause of infective esophagobronchialfistula in developing countries like India, with reported incidence in $27 \%$ of patients with esophageal TB. ${ }^{1}$ The treatment options include medical management with anti tubercular therapy (ATT), nutritional support with Ryle's tube (RT) or PEG, endoscopic treatment with stents, glue injection or clipping and surgical management. The over-the-scope-clip (OTSC) system (Ovesco Endoscopy GmbH, Tuebingen, Germany) is a novel device for the mechanical closure of defects in the gastrointestinal tract. Originally, OTSC was used for treatment of non-variceal gastrointestinal bleeding. ${ }^{2}$ Recently, the system has also been used to close fistulae, perforations and leaks. ${ }^{3}$ We report the unsuccessful closure of a tuberculous esophago-bronchial fistula using the OTSC system. Patient's consent was taken for publication.

\section{Case Report}

An 18-year-old boy, with tuberculous cervical and mediastinal lymphadenopathy, diagnosed on histology, was started on treatment with 4 drug antituberculous therapy (HRZE). A month later, his constitutional symptoms subsided and appetite improved. However, he started having cough after ingestion of food and water. He had pneumonia thrice in 2 months, requiring hospitalisation. Sputum examination was done after 2 months of antituberculous therapy and did not reveal acid fast bacilli. Barium esophagogram showed the presence of a fistulous track from the mid esophagus to the right lobe bronchus. Computed tomography (CT) of thorax showed mediastinal lymphadenopathy. Esophagoscopy revealed afistulous opening at $26 \mathrm{~cm}$ from the incisor teeth with normal surrounding mucosa (Figure 1).

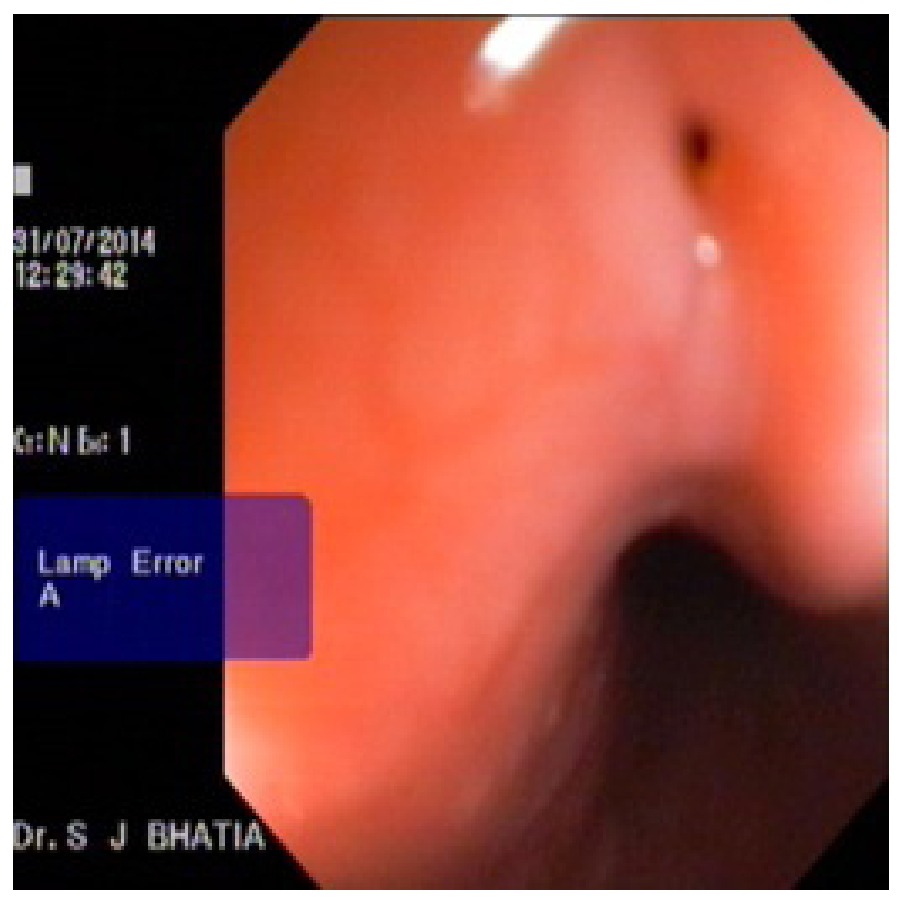

Figure 1: Fistulous opening in the esophagus with normal surrounding mucosa. 
Nasogastric (NG) tube feeding and ATT was restarted, but he was uncomfortable. A decision to close the esophagobronchial fistula was taken with over-the-scope-clip (OTSC) system (Ovesco Endoscopy GmbH, Tuebingen, Germany). The site of the esophago-bronchial fistula was identified endoscopically and the peri-fistular tissue was de-epithelialised with a gold probe. An $11 \mathrm{~mm}$ diameter OTSC was then mounted onto the endoscope. A threepronged tissue anchor was passed into the fistula to retract and invert the tissue followed by deployment of the OTSC. This resulted in effective sealing of the fistulous tract (Figure 2). Closure of the fistula was fluoroscopically confirmed indicating technical success (Figure 3). The patient was started on oral feeds on the second day. The patient had no symptoms after eating. The patient remained asymptomatic for a month after which however, he had recurrence of symptoms and esophago-bronchial fistula on esophagoscopy. Repeat OTSC was offered to the patient but he refused. Patient was treated with RT feeding and a complete course of antituberclous therapy following which his esophagobronchial fistula ultimately closed and he has remained asymptomatic till date.

\section{Discussion}

Tuberculous esophago-bronchial fistulae may result from parenchymal tuberculosis and/or necrotizing mediastinal tuberculous lymphadenitis. Tuberculous esophagorespiratory fistula may form either during the active stage of the tuberculous infection, or many years later during a quiescent phase. The mechanisms in formation of tuberculous esophago-respiratory fistula are rupture of caseous necrotic para-bronchial lymph nodes into adjacent mediastinal structures, erosion of primary tracheal ulcers into the adjacent esophagus and post infectious adhesions between tracheo-bronchial lymphnodes and the esophagus causing traction diverticulaeto rupture into the respiratory tree.

Covered self expandable metallic stents (SEMS) have been tried for management of malignant and benign fistulae but with limited success overall, due to the risk of stent migration, especially in the absence of stricture. Airway stenting has been tried in central airway and main bronchial disruptions and fistulae, but are of unproven

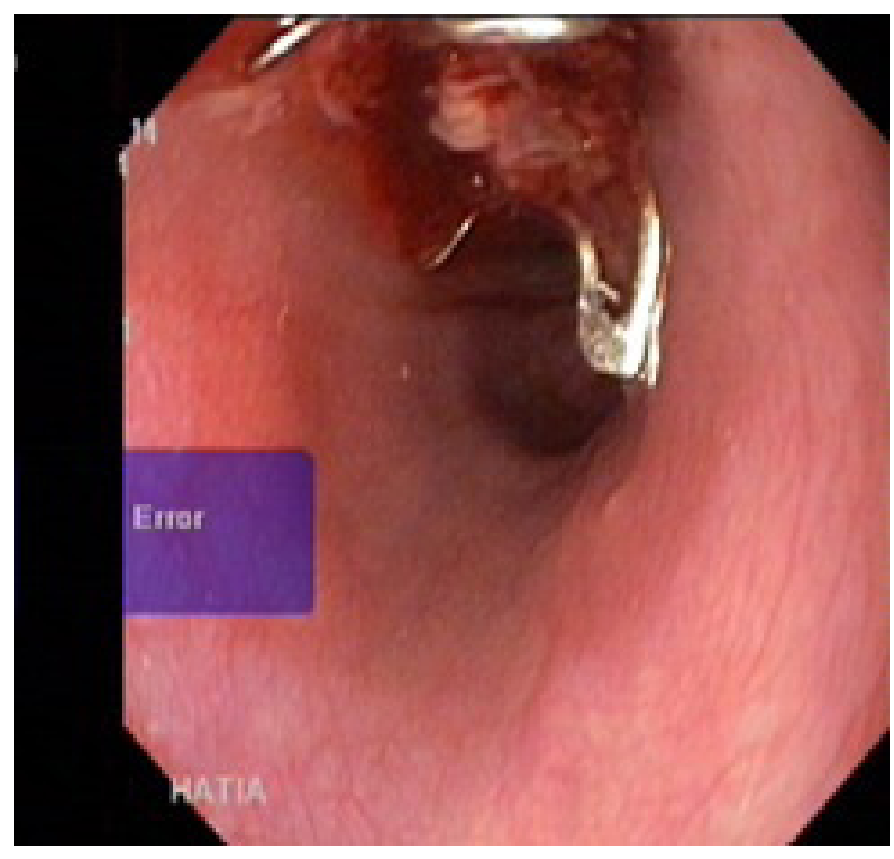

Figure 2: OTSC deployed, effectively compressing and sealing the fistulous tract.

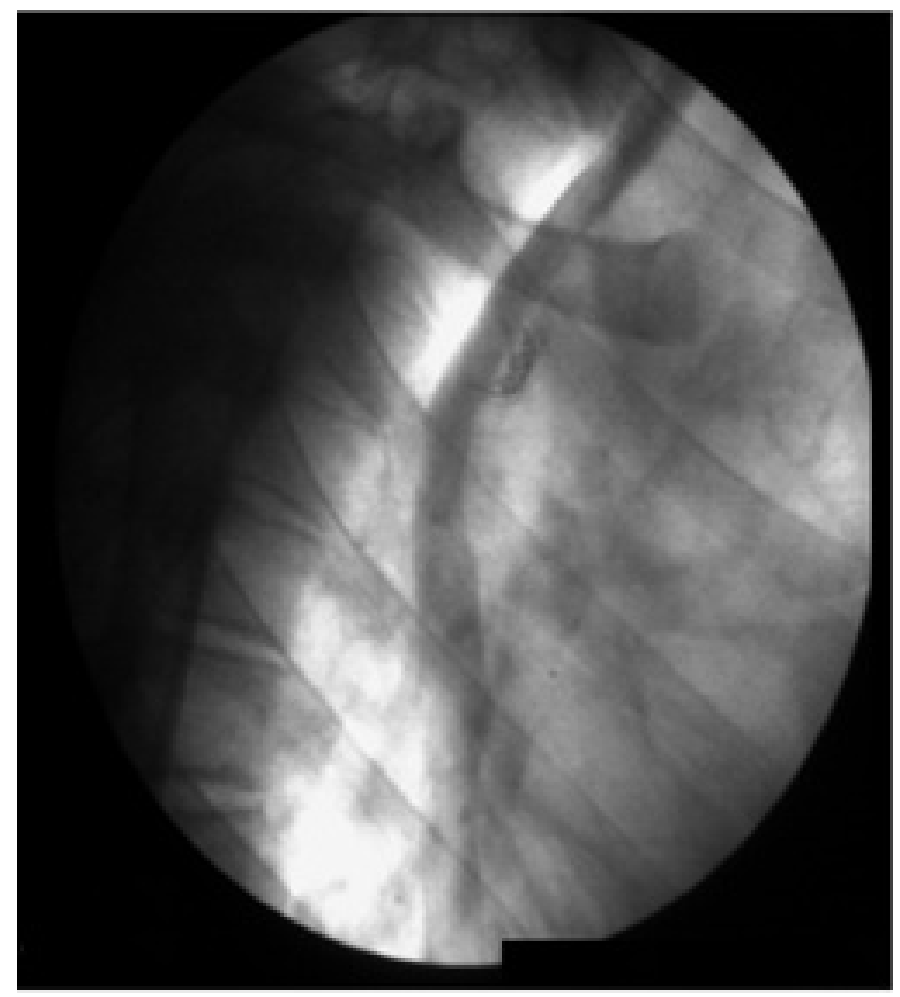

Figure 3: Barium esophagogram after a month post clipping showed no leak, with OTSC insitu. 
efficacy in benign conditions. Surgical approaches may carry a significant operative risk and result in postoperative morbidity. NG tube placement has been tried in immunecompromised patients however, it is often not tolerated. In addition, due to the potential physical contact of the catheter with the fistula, mucosal repair may not occur and can also be associated with gastro-esophageal ascending reflux/colonization along the nasogastric catheter. Enteral feeding with a PEG tube is helpful in immune-compromised patients, who may require a longer duration of medical treatment for healing of the fistula. Hemoclips may not allow for closure of large defects as they do not exert enough tensile force to keep large defects approximated. Glue, when used for closure of esophagorespiratory fistula may dislodge with cough. The OTSC system was offered for tuberculous esophago-bronchial fistula closure in our patient. This device isattached to a gastroscope and delivers an 11-mm, 12-mm,or 14-mm diameter clip capable of full thickness closureof the gut through tissue approximation. It workssimilar to a "bear trap" with the clip held open at the endof the endoscope. Upon release, the clip then closes backto its native clamshell shape.

Only a few case reports using OTSC for esophageal fistula closures have been reported previously. ${ }^{4}$ But there are no case reports for the use of OTSC system for tuberculous esophago-bronchial fistula to the best of our knowledge. In our case technical success was achieved without clinical success. The closure of chronic fistulae bears technical challenges resulting from inflammationinduced fibrotic tissue coating the orifice and inner layers of the fistula. ${ }^{5}$ In cases of persistent, highly fibrotic fistulae, complete closure may be a challenging task and this can be overcome by repeat OTSC procedures after initial technical or clinical failure, thereby increasing the success rate with second or third time clip placements. ${ }^{5}$ Our case suggests that closure of a tuberculous esophagobronchial fistula using OTSC system may not result in clinical success.

KIRAN S ABHISHEK SADALAGE ABHINAV JAIN DEEPAK GUPTA
SANGEET SAWRAV

VINIT KAHALEKAR AKASH SHUKLA

Department of Gastroenterology, KEM Hospital, Mumbai 400012

Corresponding Author: Dr Abhinav Jain Email:dra.j.12320@gmail.com

\section{References}

1. Baijal R, Ramegowda PH, Jain M, Gupta D, Shah N, Kulkarni S. Clinical profile and management of tuberculous bronchoesophageal fistula. J Dig Endosc 2013;4:103-6

2. Kirschniak A, Kratt T, Stüker D, Braun A, SchurrMO, Königsrainer A, A new endoscopic over-the-scope clip system for treatment of lesions and bleeding in the GI tract: first clinical experiencesGastrointest Endosc 2007;66(1):162-7

3. Haito-Chavez Y, Law J.K, Kratt $\mathrm{T}$ et al. International multicenter experience with an over-the-scope clipping device for endoscopic management of GI defects (with video). Gastrointest Endosc. 2014;80:610-22.

4. Traina M, Curcio G, Tarantino I, et al. New endoscopic overthe-scope clip system for closure of a chronic tracheoesophageal fistula. Endoscopy 2010;42:E54-5.

5. Weiland T, Fehlker M, Gottwald T, Schurr MO. Performance of the OTSC system in the endoscopic closure of gastrointestinal fistulae-a meta analysis. Minim Invasive Ther Allied Technol. 2012;21(4):249-58.

\section{Lost in the Giant Diverticulum - A Turn in Time of Need}

Zenker's diverticulum (ZD) is a herniation of the posterior pharyngeal wall through a natural weakness between the inferior pharyngeal constrictor and the crico-pharyngeus muscle. It is the most common type of oesophageal diverticulum with a reported prevalence ranging between 0.01 to $0.11 \%$. ZDs usually presents with 